\title{
A atividade de beneficiamento de quartzitos na cidade de Ouro Preto- Brasil: características gerais e principais impactos ambientais
}

\section{The quartzite improvement activity in Ouro Preto-Brazil: main characteristics and environmental impacts}

\author{
Mariangela Garcia-Praça Leite \\ Maria Augusta Gonçalves-Fujaco*
}

\begin{abstract}
Since late $17^{\text {th }}$ century, quartzites have been used for houses construction and road pavement in Ouro Preto. Until today, this stone is extracted from the surroundings of the city, where it is also processed. Despite of that, little is known about the characteristics of this activity. In this work, eight quartzite processing enterprises were identified, to which three open questionnaires were applied (enterprises' managers, employees and environmental issues). The enterprises have an average of 11 years of activity, hiring between 2 and 20 people. Most of the employees haven't finished elementary school and did not attend professional courses. As for environmental issues, the enterprises do not have waste management plans, which suggest that the activity is far from being sustainable.
\end{abstract}

Keywords: quartzite, processing, Ouro Preto.

\begin{abstract}
Resumo
Desde o século XVII, quartzitos vêm sendo utilizados em Ouro Preto na construção de casas, muros e ruas. Até hoje, esta rocha é extraída nos arredores da cidade, onde também é beneficiada. Porém, pouco se sabe sobre as características desta atividade. Neste trabalho, foram identificadas oito empresas de beneficiamento, nas quais foram aplicados três questionários abertos, direcionados à empresa, aos trabalhadores e o terceiro de caráter ambiental. As empresas têm em média 11 anos de atividade, empregando entre 2 e 20 homens. Os funcionários, em sua maioria, não completaram seus estudos e nunca fizeram cursos profissionalizantes. As empresas não dispóem de um plano de gestão de resíduos, o que faz com que atividade esteja longe de ser sustentável.
\end{abstract}

Palavras-chave: quartzito, beneficiamento, Ouro Preto.

* Universidade Federal de Ouro Preto, Campus Morro do Cruzeiro, Brasil. Correos-e: garcia@ degeo.ufop.bry augusta@degeo.ufop.br. 


\section{Introduçáo}

Os primeiros instrumentos confeccionados pelo homem, ainda durante a fase da pré-história, tinham a pedra como matéria prima. Desde então, seu uso vem se diversificando. Os primeiros registros de seu uso para fins ornamentais vêm da Antiguidade, nas civilizaçóes egípcias, gregas e romanas. Assim também a história de Ouro Preto/MG está ligada às rochas e minerais, inicialmente com o ouro e, hoje, em especial com o ferro. $\mathrm{O}$ quartzito apesar de nunca ter sido uma grande fonte de riqueza para a região, sempre esteve presente na vida da cidade. Desde a fundação do Arraial de Padre Faria, o quartzito vem sendo usado em construçóes de muros, passeios, meios-fios, bases de casas, pisos, dentre outras aplicaçóes.

O Brasil é um dos grandes produtores e exportadores mundiais de rochas ornamentais e de revestimento. Sua produção que totalizava 6,0 milhões toneladas/ano em 2003 (Chiodi Filho, 2004; Chiodi Filho et al., 2004), alcança, em 2008, 7.8 milhôes de toneladas/ano, com as exportaçôes atingindo US\$ 995 milhóes (Abirochas, 2009) e, caindo para um faturamento de US\$959.2 milhóes em 2010 (Abirochas, 2011). A queda do faturamento é reflexo da crise econômica mundial, já que deste total, 33,7\% são destinados ao mercado externo (Abirochas, 2011).

Os estados do Espírito Santo, Minas Gerais, Bahia e Rio de Janeiro acumulam $82 \%$ da produção brasileira de rochas. A Associação Brasileira da Indústria de Rochas Ornamentais (Abirochas, 2009) estima que em Minas Gerais existam cerca de 160 frentes ativas de lavra, com uma produção de 1.2 milhóes de toneladas/ano. Essa produçáo distribui-se por mais de 50 municípios, incluindo a extração de granitos, ardósias e quartzitos, dentre outras, que compóem quase 150 variedades comerciais colocadas nos mercados interno e externo. Ainda segundo a Abirochas (2006), mais de 1,800 empresas atuam nos segmentos de lavra, beneficiamento e marmoraria em Minas Gerais, representando investimentos privados da ordem de US\$300 milhóes, movimentando aproximadamente US\$ 220 milhóes/ano. Estas empresas geram 22,000 empregos diretos, 6,000 dos quais no segmento de lavra e 16,000 nos de beneficiamento e marmoraria.

Os materiais naturais de ornamentação e revestimento incluem as rochas que podem ser extraídas em blocos ou placas, cortadas em formas variadas e que têm suas faces beneficiadas por meio de esquadrejamento, polimento, lustro, apicoamento e flameamento. No caso dos quartzitos, por se tratarem de rochas com alto grau de recristalização e granulação predominantemente fina (quando constituídos essencialmente por quartzo), a extração será a partir de blocos, sendo possível a obtenção de chapas regulares, em teares apropriados, com posterior processo de beneficiamen- 
to envolvendo o polimento e lustro (Costa et al., 2000). De acordo com os dados da Abirochas (2011), a extração no Brasil totalizou um milhão de toneladas em 2010, entre quartzitos foliados e maciços. Deste total, estima-se que 90\% eram devidas a Minas Gerais. Em Minas Gerais, as principais áreas produtoras situam-se na região sul do estado. Nestas áreas, parte da produção já alcança o mercado europeu e norte-americano. Nas regióes de Ouro Preto (onde os quartzitos são conhecidos como Pedra Ouro Preto), Mariana e Diamantina, verifica-se uma produção irregular e voltada para atender apenas as demandas do mercado interno (Costa $e t$ al., 2000; Chiodi \& Vaz, 2002; Abirochas, 2009). Ouro Preto é o terceiro centro produtor de quartzito de Minas Gerais, só ficando atrás de São Tomé das Letras e Alvinópolis.

Segundo Pires (2007), o grande incremento da indústria de beneficiamento de quartzito, a partir da década de 70, tem acelerado a degradação ambiental. Para este autor, os principais problemas ambientais estão relacionados com a falta de controle dos depósitos de rejeitos finos e sólidos e o não tratamento da água utilizada no processo de beneficiamento, o que ocasiona impactos nos corpos d'água e no solo. Além disso, a exposição de trabalhadores das empresas de beneficiamentos às poeiras, contendo sílica cristalina, pode causar vários problemas de saúde, especialmente, doenças das vias aéreas, doenças crônicas do sistema respiratório, a silicose e até o câncer ocupacional. A silicose é uma doença pulmonar incurável, desencadeada pela inalação de poeiras contendo sílica cristalina, que se caracteriza pelo desenvolvimento de uma fibrose na regiáo do tecido pulmonar (Fundacentro, 2011).

Apesar de o Brasil, representado principalmente por Minas Gerais, estar no grupo dos grandes produtores e exportadores mundiais do setor de quartzitos, é significativo o desconhecimento acerca de toda a cadeia produtiva destas rochas ornamentais e de revestimento, especialmente do seu setor de beneficiamento. Neste contexto, o objetivo deste trabalho foi o de levantar as características sócio-econômicas e os impactos ambientais da atividade de beneficiamento de quartzitos na cidade de Ouro Preto, de forma a subsidiar açóes posteriores que promovam a sustentabilidade do setor.

\section{Materiais e métodos}

Considerando-se o objetivo geral e os específicos deste trabalho e a necessidade de selecionar e aplicar métodos e técnicas que garantissem náo só o alcance desses objetivos, mas também respostas e resultados o mais possível confiáveis, optou-se por dividir o trabalho em três diferentes fases, sucessivas, são elas: 


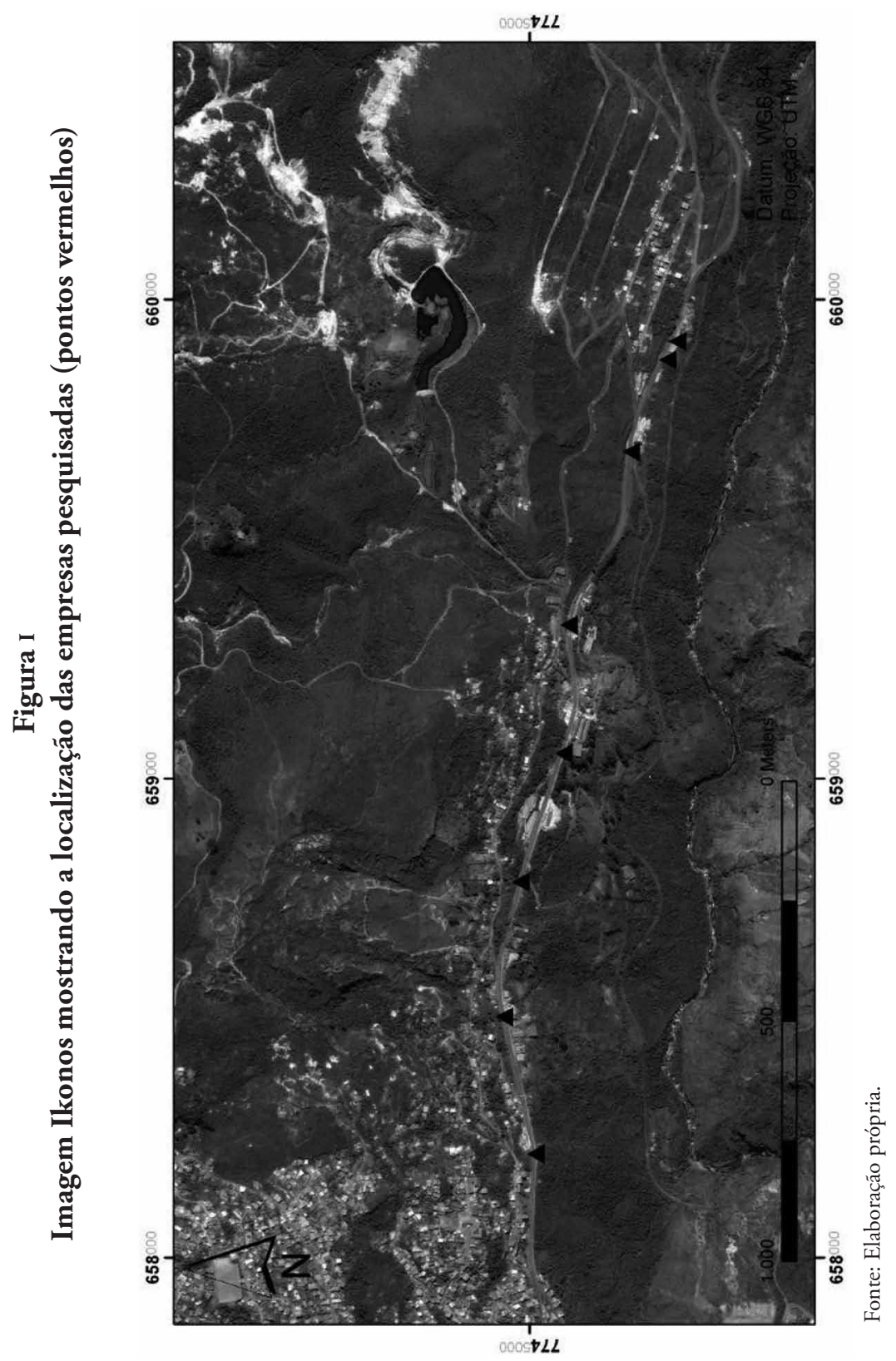


$1^{\text {a }}$ fase. Nesta fase, foram localizadas as principais unidades de beneficiamento em atividade na cidade de Ouro Preto. Inicialmente, as potenciais unidades foram identificadas em uma imagem de satélite Ikonos. De posse desta informação, deu-se início ao trabalho de campo, com o georreferenciamento das serrarias em atividade com o auxílio de um GPS (figura I). Cada serraria foi cadastrada de forma a facilita a $2^{\text {a }}$ fase do projeto.

$2^{a}$ fase. Nesta segunda etapa, foram confeccionados três questionários abertos (tabelas 1, 2 e 3), um direcionado à empresa, um voltado aos trabalhadores e o terceiro para direcionar as observaçóes de caráter ambiental. O questionário I (funcionário) continha também 20 perguntas a serem respondidas por pelo menos 2 funcionários em atividade quando da visita (18 entrevistados), que versavam sobre escolaridade, treinamento, uso de equipamentos de proteção, doenças, educação ambiental. $\mathrm{O}$ questionário II (empresa) continha 20 perguntas a serem respondidas pelo proprietário ou gerente da empresa, envolvendo questóes legais sobre a empresa, quantidade e tipo de funcionários, uso de equipamentos de segurança, produção, rejeito e efluentes. Já o questionário III, a ser preenchido pelo avaliador durante a visita, continha 23 questóes voltadas para a validação das respostas dos questionários anteriores e mais especificamente sobre as condiçóes de trabalho e destinação de resíduos e efluentes. Durante as visitas, todas as empresas foram fotografadas, dando-se ênfase aos detalhes abordados nos questionários.

$3^{\mathrm{a}}$ fase. De posse dos questionários, foi montado um banco de dados, a partir do qual foram montados gráficos e realizado um tratamento estatístico básico.

\section{Resultados}

Foram identificadas oito empresas de beneficiamento de quartzito na cidade de Ouro Preto, todas situadas às margens da rodovia dos Inconfidentes, saída para a cidade de Mariana (figura I).

\subsection{As empresas}

As empresas têm entre 0.5 e 20 anos de funcionamento, com uma média de 11 anos de atuação no mercado (figura IIa). Trata-se de empresas declaradas como de pequeno porte, que empregam entre 2 e 20 funcionários, com uma média de 9 funcionários (figura IIb). As maiores empresas possuem até $25 \%$ de funcionários indiretos, adotando a terceirização de alguns de seus serviços, como transporte e limpeza.

A produção média mensal encontrada foi de $2,430 \mathrm{~m}^{2}$, variando entre 100 e $10,000 \mathrm{~m}^{2} / \mathrm{mês}$. Resultados semelhantes aos obtidos por Pires (2007), 


\section{Tabela 1}

\section{Questionário aplicado aos funcionários das empresas}

\begin{tabular}{lcc}
\hline & Projeto Quartzito-Empresa & \\
\hline Empresa: & CNPJ: & \\
End.: & $\mathrm{n}^{\circ}:$ & Bairro: \\
& Tel: & \\
Responsável: & & \\
Entrevistado: & Cargo: \\
\hline
\end{tabular}

Quais atividades são exercidas pela empresa?

Quanto tempo a empresa atua no setor?

Quantos empregados trabalham na empresa?

Os empregados utilizam algum equipamento de segurança?

Qual a idade mínima e máxima dos funcionários?

Existe algum responsável técnico?

A própria empresa extrai o quartzito?

Quanto material entra e sai por mês na empresa?

De onde vem o quartzito que será cortado?

Quais os produtos vendidos pela empresa (placas, retalhos, etc)?

O quartzito é vendido para quais cidades?

Como é feito o transporte destes produtos?

A empresa possui banheiro? Esgoto ou fossa?

De onde vem a água usada no corte?

Para onde vai a água usada no corte?

Onde são colocados os restos do corte? Aproveitamento dos rejeitos?

Você se interessaria em uma melhoria na forma de tratamento dos restos gerado pela sua empresa?

O que você acha que deveria ser feito para essa melhoria?

Você estaria interessado em uma possível parceria com a universidade neste sentido?

Você estaria interessado em uma possível parceria com a prefeitura neste sentido?

Fonte: Elaboração própria.

durante seu trabalho de mestrado, sendo que o autor concluiu seu trabalho em 2007, quando ainda existiam 9 empresas em funcionamento. Apenas as duas empresas maiores, com mais de 16 funcionários atingiram padróes de qualidade e produtividade para colocarem seus produtos no mercado externo. As demais se limitam a atender as demandas locais e, dentro das possibilidades de cada uma, abastecer parte do mercado nacional. Todas as empresas geram produtos serrados (de várias dimensões) e irregulares (almofadadas, lajinhas, lajóes, filetes), além de outros não 


\section{Tabela 2}

\section{Questionário aplicado aos donos das empresas}

\begin{tabular}{lc}
\hline & Projeto Quartzito-Funcionário \\
\hline Empresa: & CNPJ: \\
Nome: & Idade: \\
Cidade: & Bairro: \\
Escolaridade: & Cargo: \\
\hline \multicolumn{2}{c}{} \\
\hline
\end{tabular}

Qual seu cargo na empresa?

Qual a sua carga horária de trabalho?

Quanto tempo já faz que você trabalha nesta empresa?

Sempre trabalhou com pedras?

Como você aprendeu a trabalhar com as pedras?

Houve algum curso de treinamento desde que você começou a trabalhar aqui? De que? Você recebe em seu salário alguma gratificação? (comissão)

Que tipo de roupa você usa para trabalhar?

Que tipo de calçado você usa para trabalhar?

Você utiliza algum equipamento de segurança? Qual sua opinião sobre o uso deste tipo de equipamento?

Você faz exame de rotina para avaliar a condição de sua saúde?

Qual foi a última vez que você adoeceu? Qual o motivo? Qual a doença?

Você mora longe do trabalho? Pega condução?

Quanto tempo você demora para chegar no trabalho?

Quantas pessoas dependem de você?

Você acha que o seu trabalho prejudica a natureza? Como:

Você fica incomodado com o barulho das máquinas?

A poeira te atrapalha?

O que poderia ser feito para melhorar isso?

Vocês já receberam alguma queixa de vizinhos ou da prefeitura?

Fonte: Elaboração própria.

especificados, representados, em geral, por degraus, rodapés, cubos, peças tamboradas ou polidas, etc. (figura III).

Estima-se que a produção total seja por volta $4.2 \mathrm{mil}$ toneladas/mês, ou seja, 50,000 toneladas/ano ( $0.5 \%$ da produção nacional), o que representa um faturamento anual de cerca de $\mathrm{R} \$ 8^{\prime} 400,000.00$ (aproximadamente \$ 4’950,000.00). 


\section{Tabela 3}

\section{Questionário preenchido a partir das informaçóes obtidas pela observaçáo do recenseador sobre os aspectos ambientais e de trabalho da empresa}

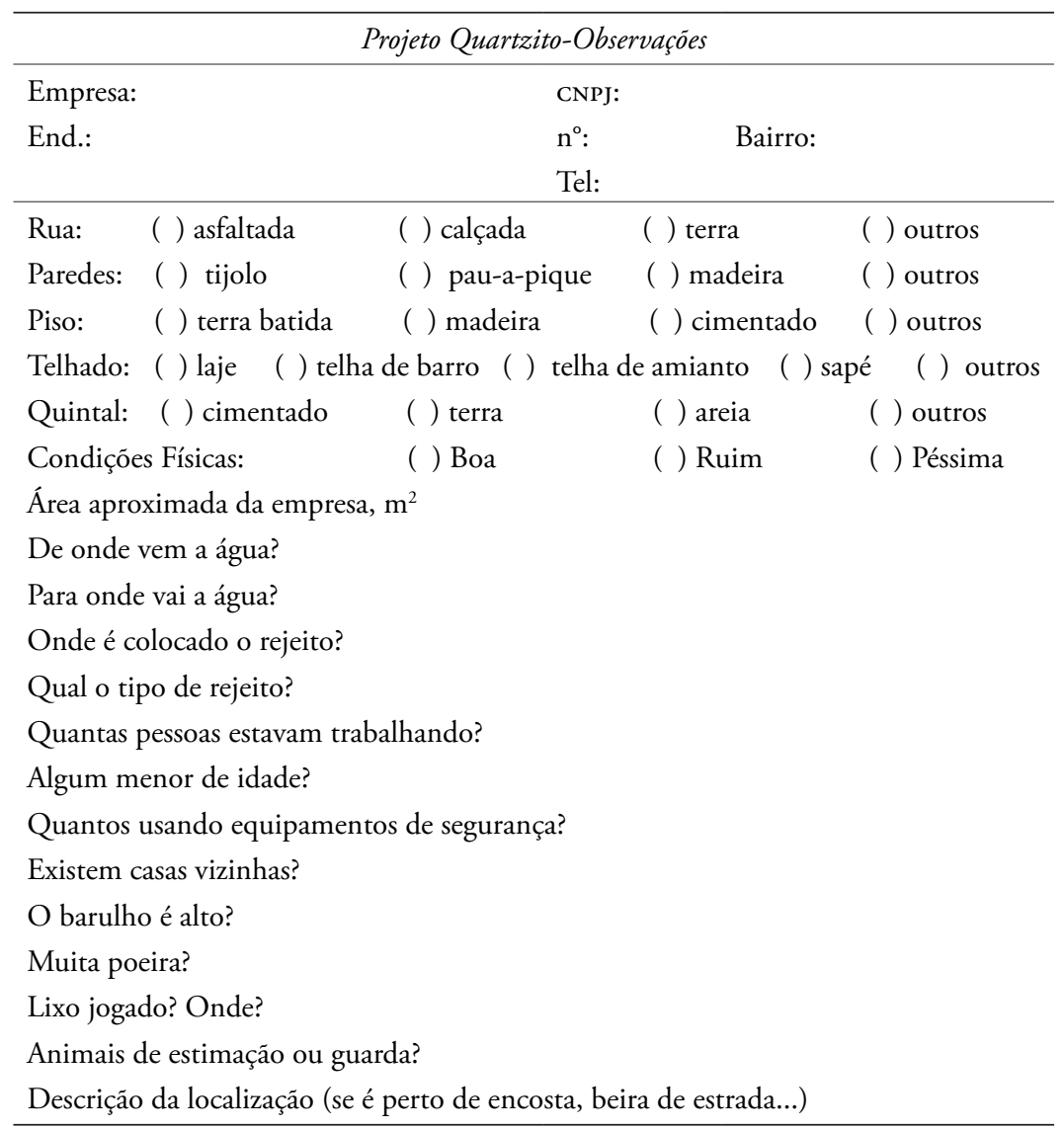

Fonte: Elaboração própria.

\subsection{Os funcionários}

Os funcionários possuem entre 19 e 41 anos, com uma média de idade de 27 anos (figura Iva). Alguns recém contratados ( 2 meses de casa) até alguns com mais de 10 anos de contrato, numa média de 5 anos de tempo de casa (figura Ivb). Em termos de escolaridade (figura IVc), 56\% possuem o primeiro grau incompleto, 33\% o primeiro grau (antiga oitava série) completo e apenas $11 \%$ possuem o segundo grau completo (atual ensino médio), mesmo assim, nenhum havia recebido treinamento especial, tendo aprendido o oficio como os funcionários mais antigos. A 


\section{Figura II}

Gráficos mostrando a distribuiçáo de anos de atividade (a) e quantidade de funcionários (b) das empresas entrevistadas
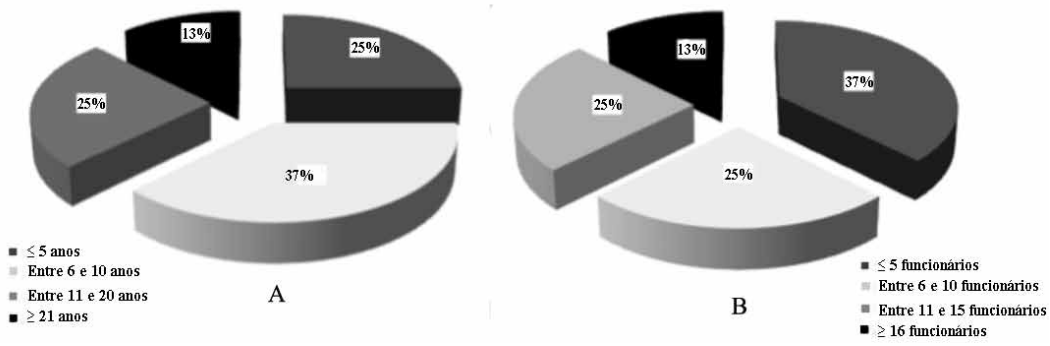

Fonte: Elaboração própria.

Figura III

Alguns dos diversos produtos oriundos do beneficiamento de quartzito na cidade de Ouro Preto

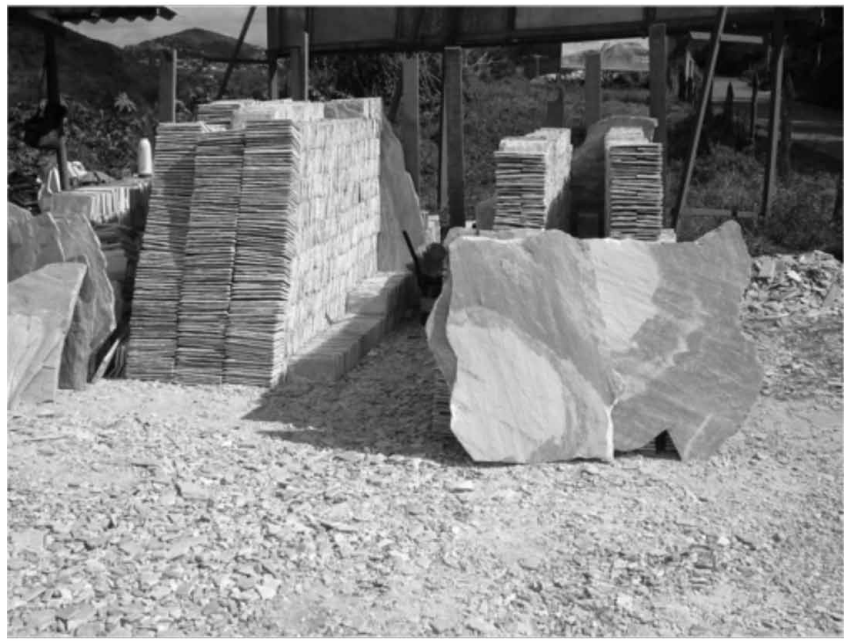

Foto: Mariangela Garcia-Praça Leite.

maioria é arrimo de família (figura IVd), sendo que $78 \%$ possuem um ou mais dependentes. Todos declaram trabalhar 8 horas/dia, mas relatam que dependendo do movimento podem trabalhar até 10 horas.

À exceção das duas maiores empresas de beneficiamento de quartzito de Ouro Preto, as demais apresentam um número muito reduzido de trabalhadores, se enquadrando entre as chamadas empresas familiares, caracterizadas por relaçóes de trabalho bastante informais, baseadas no grau parentesco de seus proprietários e trabalhadores. 
As empresas gastam de 10 a $60 \%$ do faturamento com o pagamento de empregados, que recebem entre $\mathrm{R} \$ 500.00$ (aproximadamente $\$ 295.00$ ) e R $\$ 1,200.00$ (aproximadamente $\$ 705.00$ ) por mês.

Dos entrevistados, $77 \%$ disseram usar equipamentos de proteção individual (EPI, figuras IVa, Ivb, va e vb), mas apenas 67\% realizavam exames periódicos de saúde. Os trabalhadores da maioria das empresas alegam não utilizar os EPIs disponíveis em virtude do desconforto gerado pelo seu uso. Apenas $20 \%$ dos funcionários admitem realizar exames periódicos.

\subsection{Impactos ambientais}

As observaçôes locais mostraram que as empresas recebem o quartzito na forma de blocos irregulares, acarretando elevadas perdas durante as etapas posteriores de beneficiamento. Os blocos são inicialmente transformados em lajes ou pequenos blocos de $23 \times 11.5 \times 1.5 \mathrm{~cm}$ em equipamentos de corte circular com disco diamantado (serras), refrigerados à água. Essa etapa é responsável pela geração da maior parte dos resíduos grossos (sobras do corte, chamadas localmente de aparas) e, também, do efluente, formado pelo pó de rocha gerado no corte misturado à água utilizada na refrigeração das serras (figuras va, ve e vf). Os bloquinhos são transformados manualmente em lajinhas (produto final) por meio de golpes de espátula e maceta na direção de foliação da rocha (figura vf). A fratura dos bloquinhos ocasionada por impactos mal dimensionados ou por atingirem alguma região de clivagem da rocha também é responsável pela geração de resíduos grossos, denominados de cacos.

Em termos numéricos, $62.5 \%$ das empresas não possuem água encanada, $87.5 \%$ náo dão destino adequado para o fluente líquido (figuras ve e vf). A atividade de serragem das pedras demanda volume exagerado de água. Essa água vai sendo descartada durante o processo de serragem, e alcança os córregos e rios, gerando perda e contaminação desse recurso natural. Somente uma empresa possui instalaçóes para tratamento e reaproveitamento da água utilizada. A maioria das empresas não apresenta nem ao menos sistemas de contenção do efluente gerado no corte, fazendo com que os trabalhadores estejam em permanente contato com a água. Muitas vezes, foram verificados operários trabalhando com água na altura do tornozelo.

Já no que tange os rejeitos, $62.5 \%$ não tem destino apropriado para os resíduos sólidos (figuras vc, vd e vf). São basicamente três tipos de rejeitos sólidos: as aparas (pedaços menores de quartzito sem valor de mercado), sólidos finos na forma de polpa e particulados. Os rejeitos sólidos depositados nas encostas, em áreas próximas das empresas, sem 


\section{Figura IV}

\section{Gráficos mostrando a distribuiçáo de idade dos funcionários entrevistados (a), seu tempo de contrato (b), escolaridade (c) e o número de dependentes $(\mathrm{d})$}
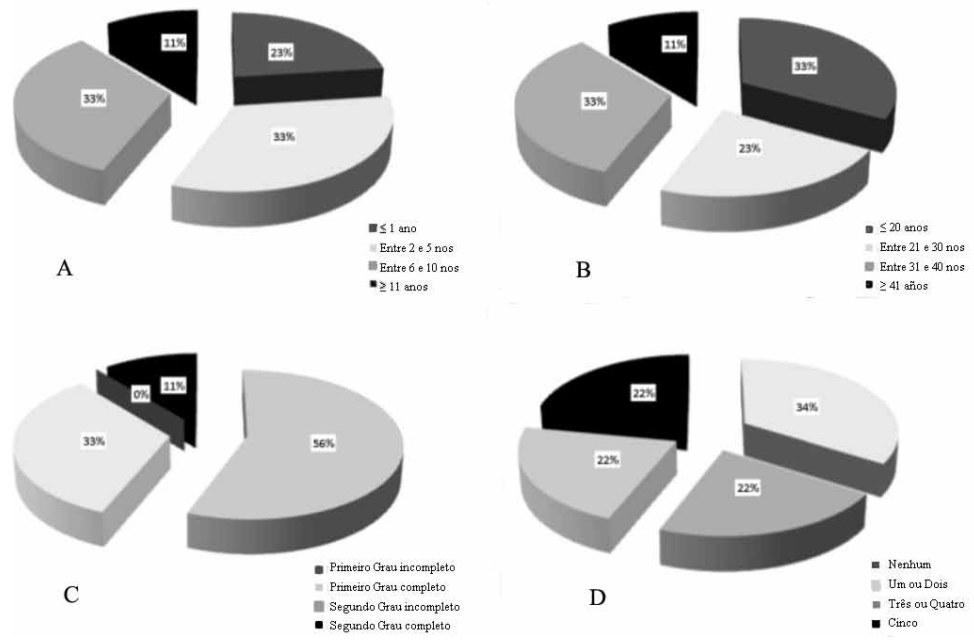

Fonte: Elaboração própria.

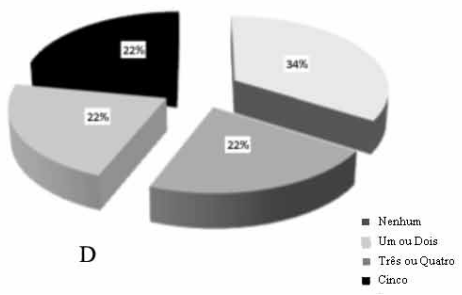

nenhum planejamento ou técnica, provocando poluição visual, riscos de escorregamento e os danos sobre a mata ciliar do ribeirão do Carmo (figuras vc e vd). O rejeito fino, em forma de polpa, tem sido descartado também nas encostas, alcançando o ribeirão do Carmo, ocasionando aumento de sua carga de sedimentos em suspensão e turbidez (figura ve), contribuindo com o assoreamento do curso d'água. Além disso, nenhuma das empresas possui equipamentos para redução da emissão de particulados na atmosfera (figura va). A ausência de filtros aliada à não utilização de EPIs podem levar a um amento no índice de doenças respiratórias, especialmente a silicose.

\section{Discussóes}

O quartzito tem um papel fundamental não só na história como na vida atual da cidade de Ouro Preto. Suas peças são encontradas em todas as ruas e na grande maioria das residências da cidade. Apesar disso, o processo de explotação e beneficiamento desta rocha ornamental ainda são artesanais e fortemente impactantes.

A falta de profissionalismo prevalece na quase totalidade das empresas, tanto do ponto de vista tecnológico quanto organizacional. Ainda assim, o beneficiamento desta rocha ainda é fonte de emprego e renda impres- 


\section{Figura $v$}

Fotografias representativas das atividades de beneficiamento do quartzito na cidade de Ouro Preto
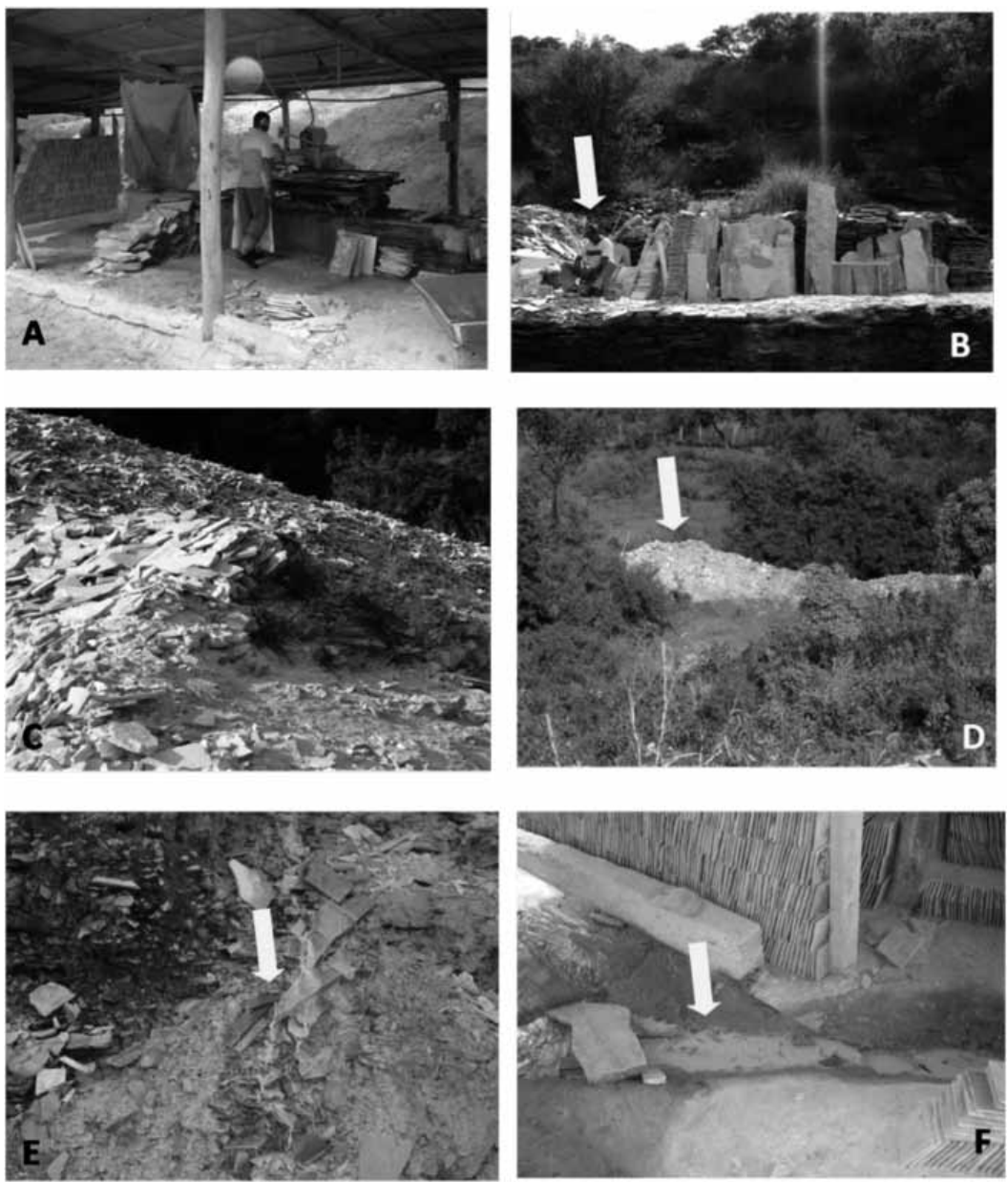

$A$ e $b$ : representação do processo de beneficiamento com maquinário $(a)$ e manual $(b)$, notar o uso incompleto de EPI; $c$ e $d$ : detalhes do rejeito, notar a total falta de organização e planejamento; $e$ e $f$ : detalhe dos efluentes provenientes das unidades de beneficiamento, notar que a quantidade de sedimentos em suspensão na água que corre livre (ver setas), sem qualquer contenção ou tratamento, sendo lançada diretamente no ribeirão do Carmo.

Foto: Mariangela Garcia-Praça Leite.

cindível para a uma parte da população mais carente, além de gerar lucros para os alguns empresários, enfatizando a vocação de Ouro Preto para a mineraçáo. As empresas pesquisadas mostram uma grande heterogeneidade que vai desde o número de trabalhadores até o destino final da produção. 
Apesar da tecnologia rudimentar utilizada e da mão-de-obra ainda pouco qualificada, todas as empresas possuem uma grande variedade de produtos gerados, com demanda crescente. $\mathrm{O}$ que permite se vislumbrar um futuro promissor caso as empresas e os órgãos públicos apóiem cursos de profissionalização específicos para este setor. Isto permitiria ampliar as atividades das empresas sem grande investimento e, assim, contribuir de forma mais efetiva para a transformação sócio-econômica da região.

As serrarias não dispóem de um plano de gestâo de resíduos quer líquido ou sólido, e as iniciativas nesse sentido são ainda incipientes. $\mathrm{Na}$ maioria das empresas os resíduos sólidos são apenas dispostos em pilhas, sem qualquer tentativa de aproveitamento, inclusive comprometendo a organização da empresa. Poucas empresas separam as aparas para comercialização como filetes para construção de muros rústicos. Algumas soluçôes de baixo custo e viáveis, a curto e médio prazo, já são aplicadas em outros lugares e poderiam ser capazes de minorar os impactos ambientais produzidos pelo tratamento e comercialização das rochas quartzíticas em Ouro Preto. Por exemplo, Carvalho \& Costa (2005), relatam que em Santo Antônio de Pádua (RJ), os resíduos grossos, acumulados pelas marmorarias, são retirados periodicamente por uma empresa de Minas Gerais, que transforma as aparas em britas para construção civil. Outra alternativa verificada pelos autores para o aproveitamento dos resíduos grossos é o aproveitamento destes resíduos para a produção de seixos ornamentais. Trabalhando com os resíduos das serrarias de Ouro Preto, Lima et al. (2007) mostraram a viabilidade técnica de utilização destes na construção civil, na fundição de vidros, o que poderia resultar em uma redução de mais de $80 \%$ dos resíduos atualmente dispostos nas encostas da rodovia dos Inconfidentes. Já o controle do resíduo fino gerado durante o corte dos blocos seria fundamental para reduzir o assoreamento dos rios e córregos próximos ás serrarias. Os resíduos finos podem ser direcionados e acumulados em tanques de sedimentação, criados a partir de buracos abertos no próprio solo da empresa e devidamente selados, onde seria seco e estocado. Este material poderia, então, ser reaproveitado para fabricação de argamassas (Carvalho, 2003), cerâmica (Torres et al., 2007) ou mesmo vidro (Lima et al., 2007).

A falta de equipamentos para retirada de particulados e o baixo percentual de utilização de EPıs também são preocupantes. A sílica livre cristalina inalada na forma de quartzo ou cristobalita a partir de exposiçóes ocupacionais é cancerígena, segundo a IARC (International Agency for Research on Cancer). Diversos estudos que relacionam silicose e risco de câncer de pulmão tem demonstrado que uma pessoa exposta à inalação de partículas silicosas possui 1.5 a 6 vezes mais risco de adquirir câncer de pulmão. Além disso, em grande parte dos estudos o aumento do gra- 
diente de risco foi observado em relação à dose, a exposição cumulativa e a duração da exposição (IARC, 1997). Os funcionários das empresas não possuem planos de saúde particulares, ficando restritos ao tratamento público. Ouro Preto, que conta hoje com mais de 70,000 habitantes, possui apenas 34 centros de atendimento público e um único hospital. São somente 102 leitos disponíveis para internação. Dados do último censo mostram que $35 \%$ das mortes no município são devido a problemas respiratórios, sendo que $60 \%$ dos obtidos ocorrem entre homens acima dos 40 anos. Infelizmente, não existem trabalhos relacionando estas mortes com a profissão exercida pelas pessoas. Almiro Marcos (2009: 5), a silicose é um problema quase desconhecido pelas autoridades e "não tem registro oficial específico de casos na saúde pública do estado" (2009: 4). $\mathrm{O}$ único dado oficial conhecido é um número geral de 57 benefícios concedidos pelo Instituto Nacional de Seguridade Social (INSs), relacionados à silicose em todo o estado de Minas Gerais no ano de 2009.

\section{Conclusóes}

O processo de beneficiamento de quartzitos na cidade de Ouro Preto é uma atividade centenária, produzindo material para a construção civil desde o início do Arraial. Apesar de sua longa história, o processo de beneficiamento ainda é feito de forma amadora ou semi-profissional. Empregando mais de 100 funcionários, quase todos arrimos de família, esta atividade movimenta mais de meio milhão de reais por mês (Pires, 2007). Ainda assim, atividade está longe de ser sustentável, provocando grandes impactos ambientais.

Os resultados mostram a necessidade de mudanças no processo de beneficiamento de quartzitos na cidade de Ouro Preto. Essas mudanças vão desde a criaçáo de cooperativas, oferta de cursos profissionalizantes e de segurança no trabalho para os funcionários até a implementação de projetos de gestão de resíduos sólidos e líquidos.

\section{Agradecimentos}

As autoras desejam registrar o seu agradecimento à Prefeitura Municipal de Ouro Preto, que gentilmente cedeu a imagem de satélite utilizada neste trabalho.

\section{Referências}

Abirochas (Associação Brasileira da Industria de Rochas Ornamentais) (2006), Consumo interno, perfil de utilização e estrutura de comer- 
cialização das rochas ornamentais e de revestimento no Brasil, Abirochas, São Paulo.

Abirochas (Associação Brasileira da Industria de Rochas Ornamentais) (2009), Os Quartzitos De São Thomé Das Letras, Minas Gerais: Principais Demandas Para O Desenvolvimento Sustentável Da Atividade Produtiva, Abirochas, São Paulo.

Abirochas (Associação Brasileira da Industria de Rochas Ornamentais) (2011), Sintese das Exportaçóes e Importaçóes Brasileiras de Rochas Ornamentais e de Revestimento em 2010, Abirochas, São Paulo.

Carvalho, Eduardo Augusto de e Marília Stella Vaz Costa (2005), "Panorama do Beneficiamento de Rochas Ornamentais em Santo Antônio de Pádua (RJ)", in Anais do I Congresso Internacional de Rochas Ornamentais, Abirochas, Guarapari, pp. 1-6.

Carvalho, Eduardo Augusto de (2003), "Aproveitamento dos Resíduos Finos da Serrarias de Santo Antônio de Pádua", en Anais do I Seminário de Sustentabilidade Ambiental da Mineração, IBram, Salvador, pp. 91-96.

Chiodi Filho, Cid e Marcos Tadeu Vaz de Melo (2002), Panorama do Setor de Rochas Ornamentais e de Revestimento de Minas Gerais, Coming-Geoxplore, Belo Horizonte.

Chiodi Filho, Cid (2004), "Evolução do Setor de Rochas Ornamentais e o Parque de Beneficiamento", Revista Pedras do Brasil, ano III, 32, São Paulo, pp. 44-52.

Chiodi Filho, Cid, Eleno de Paula Rodriguez, Antônio Carlos Artur (2004), "Panorama Técnico-Econômico do Setor de Rochas Ornamentais no Brasil”, Geociências, 23 (1-2), unesp, São Paulo, pp. 5-20.

Costa, Antônio Gilberto, Marcos Santos Campello e Vitor Brugnara Pimenta (2000), "Rochas Ornamentais e de Revestimento de Minas Gerais: Principais Ocorrências, Caracterização e Aplicaçóes na Indústria da Construção Civil", Geonomos, 8 (1), Minas Gerais, pp. 9-13. 
Fundacentro (2011), Ministério do Trabalho e Emprego, Portal da Saúde e Segurança do Trabalhador. Sílica e Silicose, <http://www.fundacentro.gov.br/index.asp? $\mathrm{D}=\mathrm{SES}>$, fevereiro.

IARC (Internacional Agency for Research on Cancer) (1997), Silica Some Silicates Coal Dust and Para-Aramid Fibrils, IARC Monographs on the Evaluation of the Carcinogenic Risk of Chemicals to Humans, vol. 38, IARC, Lyon.

Lima, Rosa Malena Fernandes, Alexandro Fortes Simóes da Silva, Rubhia Marianna Maciel de Morais, José Aurélio Medeiros da Luz (2007), "Caracterização tecnológica de resíduos de pedreiras de quartzito da regiāo de Ouro Preto/MG”, Revista Escola de Minas, 60 (4), Ouro Preto, pp. 663-668.

Marcos, Almiro (2009), "Silicose, Mal Silencioso em Pirenópolis. O Popular”, Goiânia, 24, pp. 4-5.

Pires, Paulo Roberto (2007), "Caracterização Sócio-Econômica e Ambiental da Atividade do Tratamento de Quartzito na Região de Ouro Preto", dissertação de mestrado, Programa de Pós-Graduação em Engenharia Ambiental, Ufor, Ouro Preto.

Torres, Paula Maria da Costa, Rodrigues Salvador Manjate, Sandra Quaresma, Hugo Alexandre Gonçalves da Rocha Fernandes e José Maria da Fonte Ferreira (2007) "Development of ceramic floor tile compositions based on quartzite and granite sludges", Journal of the European Ceramic Society, 27, issue 16, pp. 4649-4655.

Recibido: 9 de marzo de 2010. Reenviado: 10 de marzo de 2011. Reenviado: 7 de junio de 2011. Aceptado: 11 de julio de 2011.

Mariangela Garcia-Praça Leite. É doutora em engenharia civil, na área de recursos hídricos, pela coppe, Universidade Federal do Rio de Janeiro, Brasil. Atualmente é professora do Departamento de Geologia da Universidade Federal de Ouro Preto-Brasil e pesquisadora do Programa de Pós-Graduação em Evolução Crustal e Recursos Naturais da mesma Universidade. É orientadora de mestrado e doutorado, com diversos projetos de pesquisa financiados pela Fundação de Ampara à Pesquisa de 
Minas Gerais. Sua linha de pesquisa atual trata dos impactos ambientais da mineração, especialmente sobre os recursos hídricos. Entre suas últimas publicaçóes destacam-se: "A long-term annual water balance analysis of the Araçuaí River Basin, Brazil”, Journal of Geographical Sciences, 2, Springer, Berlin, pp. 938-946 (2010); "Agricultural influence on the hydrogeochemistry of the sub-basins of the Verde, Entre Ribeiros and Escuro Rivers of Paracatu Hydrographic Basin (MG) Brazil”, Management of Environmental Quality, 21, Emerald, Reino Unido, pp. 505-522 (2010), em co-autoria, "Influence of geology in the geochemistry signature of Itacolomi State Park waters, Minas Gerais-Brazil", Environmental Earth Sciences, 60, Springer, Alemanha, pp.1723-1730 (2010); "Environmental analysis of small rural catchments case study Melo Creek, MG/Brazil”, Management of Environmental Quality", 18, Emerald, Reino Unido, pp. 711-722 (2007).

Maria Augusta Gonçalves-Fujaco. Possui mestrado em evolução crustal e recursos naturais pela Universidade Federal de Ouro Preto (Departamento de Geologia) e doutorado em andamento pela Universidade Federal de Ouro Preto (Departamento de Geologia). Atualmente é professora do Departamento de Geologia da Universidade Federal de Ouro Preto-Brasil. A sua área de pesquisa engloba geologia ambiental, sensoriamento remoto e geoprocessamento. 